\title{
Nonlinear control of a synchronous reluctance drive system with reduced switching frequency
}

\author{
T.-H. Liu, M.-T. Lin and Y.-C. Yang
}

\begin{abstract}
A novel PWM switching method and control algorithm for synchronous reluctance drive systems is proposed. First, in different switching modes, the current slope of the stator current can be systematically derived. The current slope is related to the dc-bus voltage, operating conditions, and parameters of the motor. Then, by computing the derivation of the current slope command and the real current slope, an optimum switching state can be determined and used to trigger the inverter. After that, the nonlinear controllers for an adjustable speed drive system and a position control system are proposed. Using the proposed method, the synchronous reluctance drive system performs very well. It has smaller current harmonics, lower switching frequency, and less switching loss when compared to the hysteretic or bang-bang current control. In addition, a fast transient response, good load disturbance rejection ability, and good tracking performance of speed control and position control can be achieved. No extra hardware is required. Several experimental results validate the theoretical analysis.
\end{abstract}

\section{Introduction}

The synchronous reluctance motor (SynRM) has been recognised to have many advantages due to its simple and rugged structure. In addition, the SynRM has no winding or magnetic material on its rotor. The SynRM is shown to be very suitable for ac drive systems due to many factors. First, the field-oriented control of the SynRM does not require computing slip frequency as required for the induction motor. As a result, there is no parameter sensitivity problem [1]. Next, the SynRM does not require any permanent magnetic material as the permanent-magnet synchronous motor does [2]. Moreover, the SynRM is more suitable for a sensorless drive due to the obvious difference in d-axis inductance and q-axis inductance. As a result, it is possible to use the inductances to estimate the shaft position of the SynRM [3-6].

To achieve a high performance drive system, the motor design, PWM switching strategy, and controller design are all important. Several researchers have studied and proposed many different techniques in these fields. In PWM techniques, the most popular method is the hysteretic or bang-bang current regulated control. This method is very simple; however, it provides a highly variable PWM switching frequency. In addition, its current ripple and harmonic content are large [7]. To solve this problem, the space vector modulation is proposed. The performance of the space vector modulation is excellent; nevertheless, this method requires a lot of complicated computations. As a

\footnotetext{
(C) IEE, 2006

IEE Proceedings online no. 20050124

doi:10.1049/ip-epa:20050124

Paper first received 10th April and in final revised form 9th August 2005

T.-H. Liu and Y.-C. Yang are with Department of Electrical Engineering, National Taiwan University of Science and Technology, Taipei, Taiwan 106, Republic of China

M.-T. Lin is with Department of Electrical Engineering, Tung-Nan Institute of Technology, Taipei, Taiwan 222, Republic of China

E-mail: Liu@mail.ntust.edu.tw
}

result, a digital signal processor for space vector modulation is required [8-9]. Research on PWM strategies in induction motors or permanent magnet synchronous motors is popular; however, research on PWM strategies for synchronous reluctance motors is not common. This has motivated us to study the PWM strategy for SynRM drives. On the other hand, in the fields of motor design, motor drive, and controller design, several techniques have been proposed for SynRM drives. For example, Platt designed a new reluctance motor with strong rotor anisotropy [10]. Vagati et al. proposed a flux-observer-based control scheme to achieve a high performance SynRM drive system [11]. Sul et al. developed a high dynamic torque control for a SynRM [12]. Liu et al. implemented an $H^{\infty}$ to improve the dynamic response of a position control system for a SynRM [13]. These papers [11-13], however, only focus on linear controller design. To improve the performance of the SynRM drive system, nonlinear controllers are more effective and have been proposed. For example, Shyu et al. implemented a combination of the classical state feedback and the variable structure control [14]. The idea is good: however, a chattering problem appears in steady-state. Sul et al. proposed a nonlinear input-output linearisation technique for a SynRM. The results achieved optimal efficiency. However, the computation of the control algorithm is very complicated [15].

In this paper, a novel PWM scheme for the SynRM is proposed to improve the torque response and reduce the switching frequency. The method is based on the measurement of the current slope. Although the computation is simple, the performance of the proposed method is satisfactory. Experimental results show that this method has a lower switching frequency, lower harmonics, and better current tracking ability. In addition, in order to improve the transient response, load disturbance rejection and tracking ability, a nonlinear controller is proposed here. To the best of the authors' knowledge, this is the first time that the novel switching method and the nonlinear controller for a SynRM drive system have been proposed. The details follow. 


\section{Switching strategy}

\subsection{Dynamic model of a SynRM}

The mathematical model of a SynRM in d-q synchronous frame can be expressed as

$$
\frac{d i_{d}}{d t}=\left(\omega_{e} L_{q} i_{q}-r_{s} i_{d}+v_{d}\right) / L_{d}
$$

and

$$
\frac{d i_{q}}{d t}=\left(-\omega_{e} L_{d} i_{d}-r_{s} i_{q}+v_{q}\right) / L_{q}
$$

where $\frac{d}{d t}$ is the differential operator, $i_{d}$ is the d-axis current, $i_{q}$ is the q-axis current, $\omega_{e}$ is the electrical speed, $L_{q}$ is the q-axis inductance, $L_{d}$ is the d-axis inductance, $r_{s}$ is the stator resistance, $v_{d}$ is the d-axis voltage and $v_{q}$ is the q-axis voltage. The electro-magnetic torque expressed in the $d-q$ synchronous frame is

$$
T_{e}=\frac{3}{2} \frac{P_{0}}{2}\left(L_{d}-L_{q}\right) i_{d} i_{q}
$$

where $T_{e}$ is the electro-magnetic torque of the motor, $P_{0}$ is the number of poles of the motor, $i_{d}$ is the d-axis equivalent current and $i_{q}$ is the q-axis equivalent current. The rotor speed and position of the motor can be expressed as

$$
\frac{d}{d t} \omega_{r}=\frac{1}{J}\left(T_{e}-T_{l}-B \omega_{r}\right)
$$

and

$$
\frac{d}{d t} \theta_{r}=\omega_{r}
$$

where $J$ is the inertia constant of the motor and load, $T_{l}$ is the external load torque, $B$ is the viscous frictional coefficient of the motor and load, $\theta_{r}$ is the mechanical rotor position and $\omega_{r}$ is the mechanical rotor speed. The electrical rotor speed and position are

$$
\omega_{e}=\frac{P_{0}}{2} \omega_{r}
$$

and

$$
\theta_{e}=\frac{P_{0}}{2} \theta_{r}
$$

where $\omega_{e}$ is the electrical rotor speed and $\theta_{e}$ is the electrical rotor position of the motor.

\subsection{Proposed switching strategy}

In this paper, a new switching strategy for the SynRM is proposed. The details are discussed here. If the inverter is switched in mode $\mathrm{A}^{+}$, which is shown in Fig. 1, the switching state is $(1,0,0)$.

From Fig. 1, we can easily obtain

$$
\begin{gathered}
v_{a n}=\frac{2}{3} V_{d c} \\
v_{b n}=-\frac{1}{3} V_{d c}
\end{gathered}
$$

and

$$
v_{c n}=-\frac{1}{3} V_{d c}
$$

The relationship of the voltages between the a-b-c axis to $\mathrm{d}-\mathrm{q}$ axis is

$$
\left[\begin{array}{l}
v_{d} \\
v_{q}
\end{array}\right]=\left[\begin{array}{ccc}
\sin \theta_{e} & \sin \left(\theta_{e}-\frac{2 \pi}{3}\right) & \sin \left(\theta_{e}+\frac{2 \pi}{3}\right) \\
\cos \theta_{e} & \cos \left(\theta_{e}-\frac{2 \pi}{3}\right) & \cos \left(\theta_{e}+\frac{2 \pi}{3}\right)
\end{array}\right]\left[\begin{array}{c}
v_{a n} \\
v_{b n} \\
v_{c n}
\end{array}\right]
$$

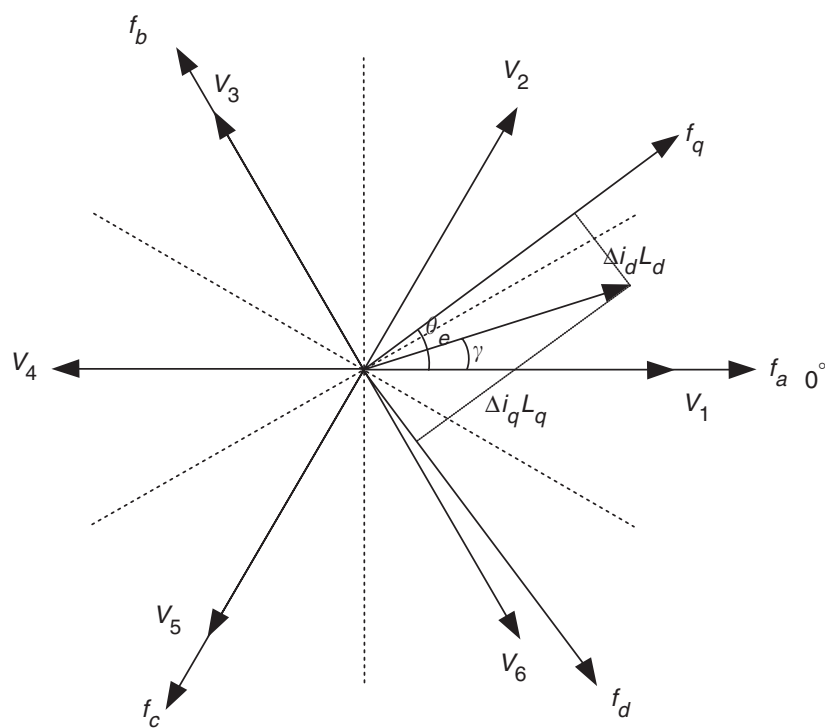

Fig. 1 The circuits of different modes $a$ Mode $A^{+}$

$b$ Mode $B^{+}$

$c$ Mode $C^{+}$

By substituting (8a), (8b) and (8c) into (9), one can obtain

$$
v_{d}=\frac{2}{3} V_{d c} \sin \theta_{e}
$$

and

$$
v_{q}=\frac{2}{3} V_{d c} \cos \theta_{e}
$$

After that, by substituting (10a) and (10b) into (1) and (2), we can derive that the dynamic equations of the $\mathrm{d}-\mathrm{q}$ axis currents can be expressed as:

$$
\left.\frac{d i_{d}}{d t}\right|_{\text {mode }^{+}}=\frac{\omega_{e} L_{q} i_{q}-r_{s} i_{d}}{L_{d}}+\frac{2}{3} \frac{V_{d c} \sin \theta_{e}}{L_{d}}
$$

and

$$
\left.\frac{d i_{q}}{d t}\right|_{\text {mode } \mathrm{A}^{+}}=\frac{-\omega_{e} L_{d} i_{d}-r_{s} i_{q}}{L_{q}}+\frac{2}{3} \frac{V_{d c} \sin \theta_{e}}{L_{q}}
$$

When the inverter is switched in a zero-voltage mode ( freewheeling mode), the switching state is $(1,1,1)$ or $(0,0,0)$. Then, the motor is three-phase shorted and is disconnected with the input voltage. The input voltage, therefore, is equal to zero. By substituting $V_{d c}=0$ into (11) and (12), one can obtain

$$
\begin{aligned}
\left.\frac{d i_{d}}{d t}\right|_{\text {mode } 0} & =\frac{\omega_{e} L_{q} i_{q}-r_{s} i_{d}}{L_{d}} \\
\left.\frac{d i_{q}}{d t}\right|_{\text {mode } 0}= & \frac{-\omega_{e} L_{d} i_{d}-r_{s} i_{q}}{L_{q}}
\end{aligned}
$$

Combining (11)-(14), one can easily obtain

$$
\begin{aligned}
& \left.\frac{d i_{d}}{d t}\right|_{\text {mode } \mathrm{A}^{+}}=\left.\frac{d i_{d}}{d t}\right|_{\text {mode } 0}+\frac{2}{3} \frac{V_{d c} \sin \theta_{e}}{L_{d}} \\
& \left.\frac{d i_{q}}{d t}\right|_{\text {mode }^{+}}=\left.\frac{d i_{q}}{d t}\right|_{\text {mode } 0}+\frac{2}{3} \frac{V_{d c} \cos \theta_{e}}{L_{q}}
\end{aligned}
$$

By using the same method, one can derive that the switching modes $\mathrm{B}^{+}$and $\mathrm{C}^{+}$have the following dynamic equations:

$$
\left.\frac{d i_{d}}{d t}\right|_{\text {mode } \mathrm{B}^{+}}=\left.\frac{d i_{d}}{d t}\right|_{\text {mode } 0}+\frac{2}{3} \frac{V_{d c} \sin \left(\theta_{e}-\frac{2 \pi}{3}\right)}{L_{d}}
$$




$$
\left.\frac{d i_{q}}{d t}\right|_{\text {mode } \mathrm{B}^{+}}=\left.\frac{d i_{q}}{d t}\right|_{\text {mode } 0}+\frac{2}{3} \frac{V_{d c} \cos \left(\theta_{e}-\frac{2 \pi}{3}\right)}{L_{q}}
$$

and

$$
\begin{aligned}
& \left.\frac{d i_{d}}{d t}\right|_{\text {mode } \mathrm{C}^{+}}=\left.\frac{d i_{d}}{d t}\right|_{\text {mode } 0}+\frac{2}{3} \frac{V_{d c} \sin \left(\theta_{e}-\frac{2 \pi}{3}\right)}{L_{d}} \\
& \left.\frac{d i_{q}}{d t}\right|_{\text {mode } \mathrm{C}^{+}}=\left.\frac{d i_{q}}{d t}\right|_{\text {mode } 0}+\frac{2}{3} \frac{V_{d c} \cos \left(\theta_{e}-\frac{2 \pi}{3}\right)}{L_{q}}
\end{aligned}
$$

To realise the proposed method, first we measure the current slope in the free-wheeling switching state. Then, we compute the desired d-axis current slope between the current command $i_{d}^{*}$ and the real current $i_{d}$, and the desired q-axis current slope between the current command $i_{q}^{*}$ and the real current $i_{q}$, which are expressed as:

$$
\left(\frac{d i_{d}}{d t}\right)^{*}=\frac{i_{d}^{*}-i_{d}}{T}
$$

and

$$
\left(\frac{d i_{q}}{q t}\right)^{*}=\frac{i_{q}^{*}-i_{q}}{T}
$$

where $\left(d i_{d} / d t\right)^{*}$ is the desired current slope, and $\mathrm{T}$ is the switching interval of the inverter. After that, we can compute the current deviation between the desired current slope and the current slope at mode 0 :

$$
\Delta i_{d}=\left(\left(\frac{d i_{d}}{d t}\right)^{*}-\left.\frac{d i_{d}}{d t}\right|_{\operatorname{mode} 0}\right) T
$$

and

$$
\Delta i_{q}=\left(\left(\frac{d i_{q}}{d t}\right)^{*}-\left.\frac{d i_{q}}{d t}\right|_{\text {mode } 0}\right) T
$$

The required voltage vector angle is

$$
\gamma=-\tan ^{-1}\left(\frac{L_{d} \Delta i_{d}}{L_{q} \Delta i_{q}}\right)+\theta_{e}
$$

Finally, the voltage vector of the inverter can be selected according to the vector angle $\gamma$. In Fig. 1, for example, the vector $V_{1}$ is selected when $\gamma$ is between $-30^{\circ}$ and $30^{\circ}$. In the real world, if the required voltage amplitude is small, we choose a free-wheeling voltage vector to reduce the current harmonics.

\section{Nonlinear controller design}

Many papers have proposed different control methods to improve the dynamic performance of synchronous reluctance drive systems. For example, Thanaa et al. proposed a sliding mode controller for position control of a vectorcontrolled synchronous reluctance drive system. The results are satisfactory; however, the control method requires knowing the parameter variation bounds of the motor. In addition, a boundary layer is required to alleviate the chattering problem [16]. Lee et al. used the feedback linearisation technique to obtain an efficiency-optimised direct torque control. The idea is of great interest; however, the controller is very complicated and requires a lot of computations [15]. Liu et al. proposed an $H^{\infty}$ controller to improve the transient response and load disturbance response of a position control system for a synchronous reluctance motor. The experimental results are satisfactory; however, the controller is complicated [17]. Chiang et al. proposed an integral variable structure controller with grey prediction for a synchronous reluctance drive system. The method can significantly reduce chattering and steady-state error; however, the control method requires a lot of computing time using a digital signal processor [18]. Recently, Shyu et al. proposed a state feedback controller combined with a variable structure controller for position control of a synchronous reluctance motor. The idea is new and interesting; however, a chattering problem exists due to the high frequency switching of the variable structure controller [19].

In order to reduce the complexity of the controllers mentioned above [15-19], this paper proposes a simple nonlinear controller for a SynRM drive system. Only the error signal is used here. By combining the integral and proportional items of the error signal and its nonlinear operation, a control input can be obtained. A systematic stability analysis of the control system is discussed. The proposed method can be applied for a speed control system and a position control system. To the authors' best knowledge, this is the first time that the proposed method has been applied to a SynRM drive system. The details are shown as follows.

\subsection{Speed-loop controller}

The block diagram of the closed-loop speed control system is shown in Fig. $2 a$. To obtain a nonlinear controller, the control input of the drive system is selected as

$$
u=G_{e} \frac{\partial V}{\partial e}+G_{i} \int \frac{\partial V}{\partial e} d t
$$

where $u$ is the control input, $G_{e}$ is the proportional gain, $G_{i}$ is the integral gain, $V$ is the Lyapunov function, $e$ is the error between the command and output, $d$ is the differential operator and $t$ is time. In this paper, the Lyapunov function is selected as [20]:

$$
V(e)=\frac{3}{4} K_{p 0} e^{\frac{4}{3}}+\frac{1}{2} K_{p 1} e^{2}+\frac{3}{4} K_{i 0} e^{\frac{4}{3}}+\frac{1}{2} K_{i 1} e^{2}
$$

The general results in stability theory were developed by Lyapunov. As we know, Lyapunov formulated a basic concept of stability and derived sufficient stability conditions for dynamic systems, described by ordinary differential equations. In recent years, there has been considerable research in developing innovative non-quadratic forms of Lyapunov candidate. The application of efficient and flexible software, such as MATLAB, has changed the aim of the Lyapunov theory. Owing to the improvement of the computing ability for software, the value of Lyapunov's theory is shifted from the descriptive theory to the design of stabilising controllers. The Lyapunov concept is a viable tool in solution of stabilisation and optimisation problems, encountered in the wide areas of control [20]. The basic motivation of this paper is to apply the Lyapunov concept to design nonlinear controllers for a synchronous reluctance drive system. As a result, the fractional powers of the error signal are selected. It is demonstrated that the application of the complicated Lyapunov candidates is an important step. This allows one to design a high performance nonlinear controller. In this paper, the Lyapunov concept is used to 

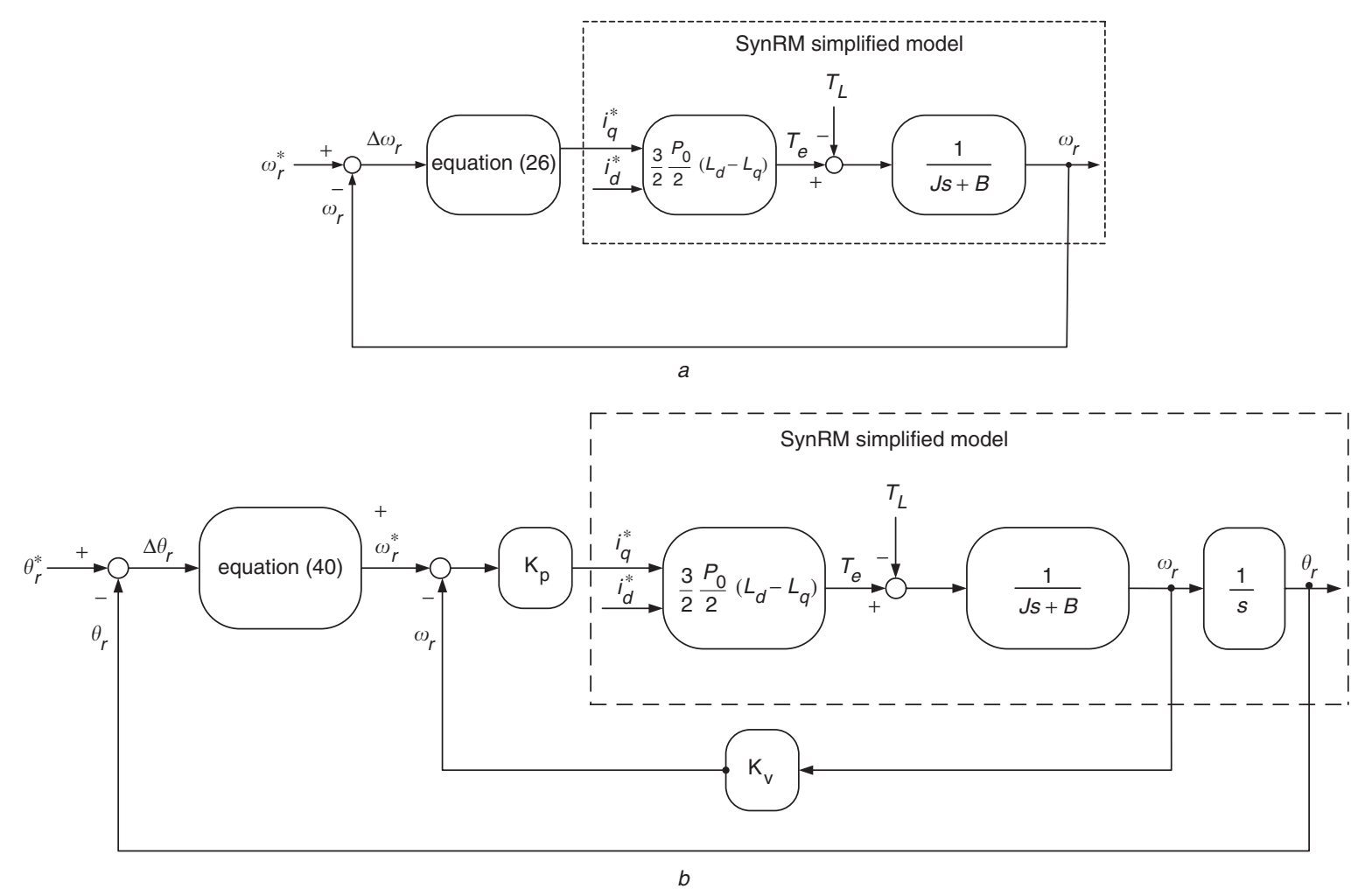

Fig. 2 The block diagram of the proposed system

$a$ Speed control system

$b$ Position control system

design both a speed controller and a position controller for the synchronous drive systems.

By substituting (27) into (26), one can obtain

$$
\begin{aligned}
u= & i_{q}^{*}=G_{e}\left(K_{p 0}+K_{i 0}\right) e^{\frac{1}{3}}+G_{e}\left(K_{p 1}+K_{i 1}\right) e \\
& +G_{i}\left(K_{p 0}+K_{i 0}\right) \int e^{\frac{1}{3}} d t+G_{i}\left(K_{p 1}+K_{i 1}\right) \int e d t
\end{aligned}
$$

In order to simply the expression of (28), we define

$$
\begin{aligned}
& K_{p n}=G_{e}\left(K_{p 0}+K_{i 0}\right) \\
& K_{p e}=G_{e}\left(K_{p 1}+K_{i 1}\right) \\
& K_{i n}=G_{i}\left(K_{p 0}+K_{i 0}\right) \\
& K_{i e}=G_{i}\left(K_{p 1}+K_{i 1}\right)
\end{aligned}
$$

Then, the control input of the drive system can be expressed as

$$
u=K_{p m} e^{\frac{1}{3}}+K_{p e} e+K_{i n} \int e^{\frac{1}{3}} d t+K_{i e} \int e d t
$$

We can observe that the first and third terms are increased as compared with the traditional PI controller. In fact, the first and third terms are used to provide an extra effort to improve the dynamics of the system including transient response and load disturbance response.

\subsection{Position-loop controller}

The block diagram of the closed-loop position control system is shown in Fig. $2 b$. From Fig. $2 b$, we can obtain

$$
i_{q}^{*}=K_{p}\left(\omega_{r}^{*}-K_{v} \omega_{r}\right)
$$
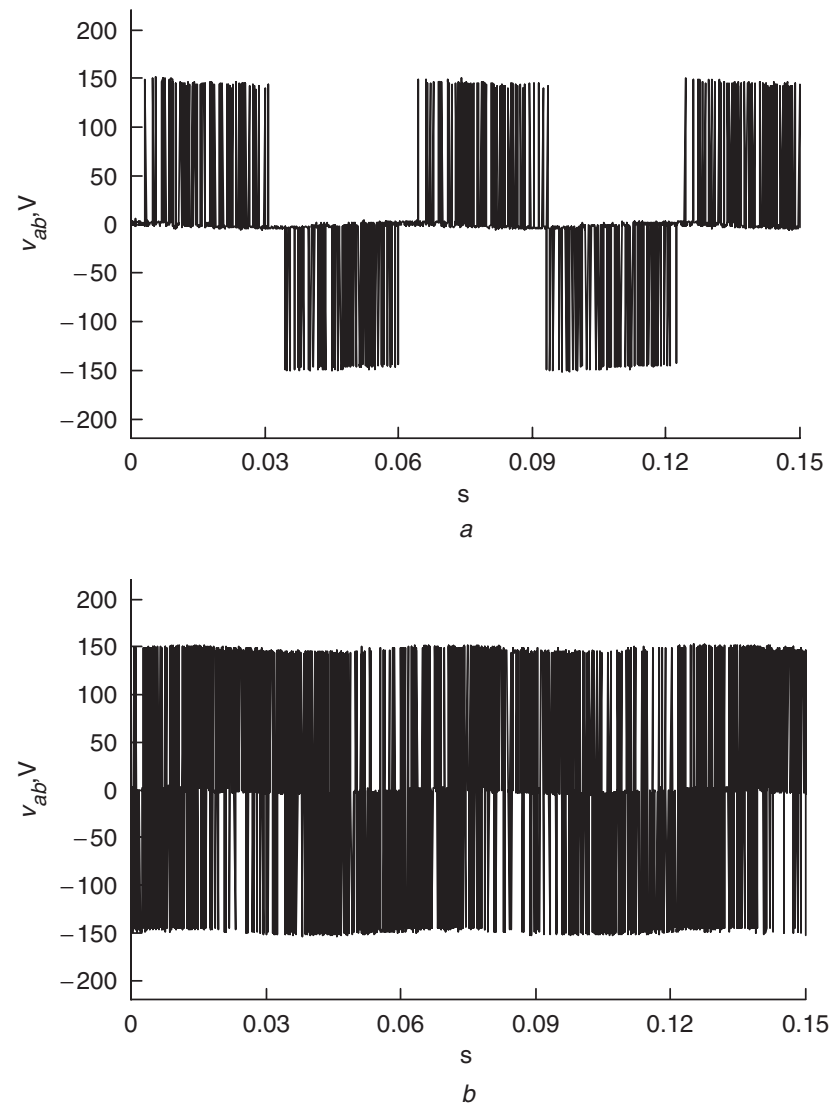

Fig. 3 The voltage $v_{a b}$ at a steady-state $a$ Proposed

$b$ Bang-bang

By substituting (34) into (3) and (4), we can derive

$$
\dot{\omega}_{r}=\frac{K_{t}^{\prime}}{J} K_{p}\left(\omega_{r}^{*}-K_{v} \omega_{r}\right) \frac{T_{L}}{J}
$$


Define the position error as

$$
e_{\theta}=\theta_{r}^{*}-\theta_{r}
$$

By taking the derivative of (36), we can obtain

$$
\dot{e}_{\theta}=\dot{\theta}_{r}^{*}-\dot{\theta}_{r}
$$

To obtain a nonlinear position controller, the control input of the position control system is selected as

$$
\begin{aligned}
u= & G_{e p} \frac{\partial V\left(e_{\theta}, \omega_{r}\right)}{\partial e_{\theta}}+G_{i p} \int \frac{\partial V\left(e_{\theta}, \omega_{r}\right)}{\partial e_{\theta}} d t \\
& +G_{x p} \frac{\partial V\left(e_{\theta}, \omega_{r}\right)}{\partial \omega_{r}}
\end{aligned}
$$

where $G_{e p}$ is the proportional gain of the position-loop controller. $G_{i p}$ is the integral gain of the position-loop controllers, and $G_{x p}$ is the feedback gain of velocity.

In this paper, the Lyapunov function of the position control system is selected as [20]:

$$
\begin{aligned}
V\left(e_{\theta}, \omega_{r}\right)= & \frac{3}{4} K_{p 0} e_{\theta}^{\frac{4}{3}}+\frac{1}{2} K_{p 1} e_{\theta}^{2} \\
& +\frac{3}{4} K_{i 0} e_{\theta}^{\frac{4}{3}}+\frac{1}{2} K_{i 1} e_{\theta}^{2}+\frac{1}{2} K_{x 0} \omega_{r}^{2}
\end{aligned}
$$
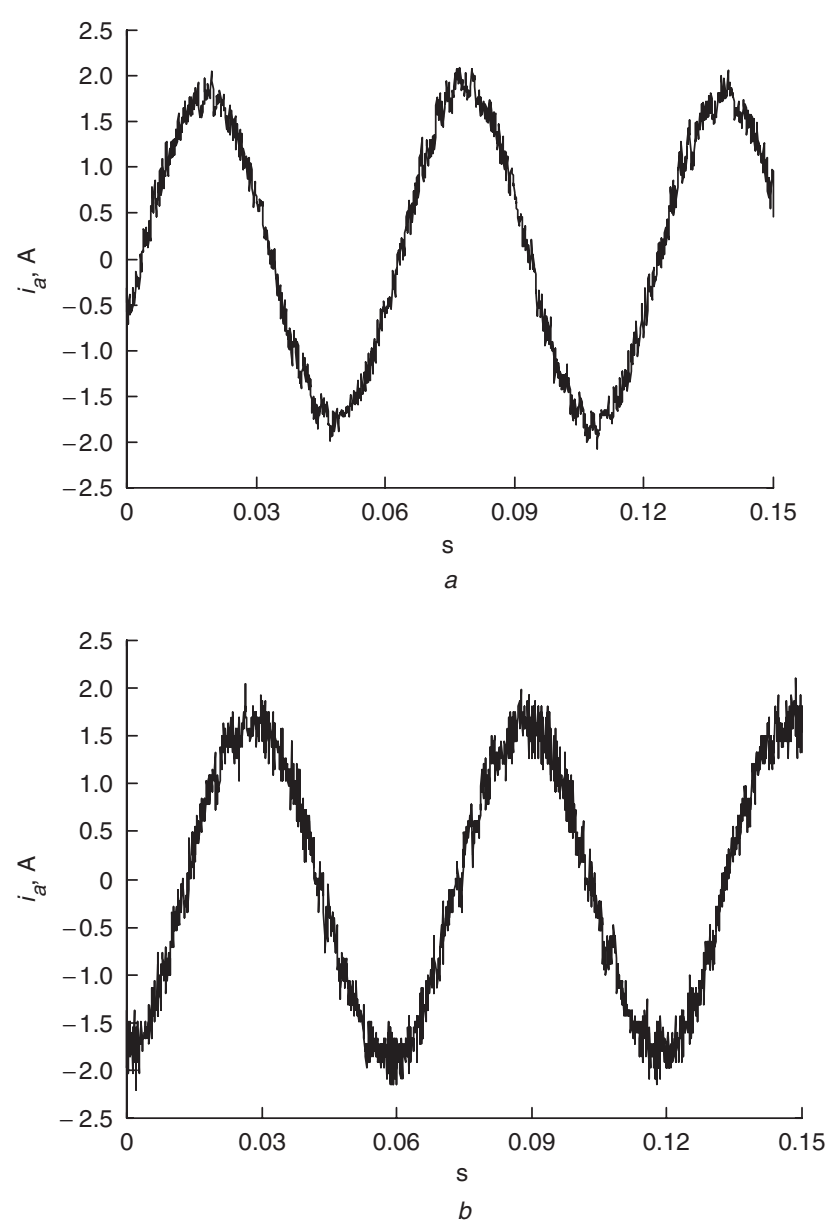

Fig. 4 The current $i_{a}$ at a steady-state $a$ Proposed $b$ Bang-bang
Substituting (39) into (38), we can obtain

$$
\begin{aligned}
u= & G_{e p}\left(K_{p 0}+K_{i 0}\right) e_{\theta}^{\frac{1}{3}}+G_{e p}\left(K_{p 1}+K_{i 1}\right) e_{\theta} \\
& +G_{i p}\left(K_{p 0}+K_{i 0}\right) \int e_{\theta}^{\frac{1}{3}} d t+G_{i p}\left(K_{p 1}+K_{i 1}\right) \\
& \times \int e_{\theta} d t+G_{x p} K_{x 0} \omega_{r}
\end{aligned}
$$

In order to simplify the expression of (40), we define

$$
\begin{gathered}
K_{p n r}=G_{e p}\left(K_{p 0}+K_{i 0}\right) \\
K_{p e r}=G_{e p}\left(K_{p 1}+K_{i 1}\right) \\
K_{i n r}=G_{i p}\left(K_{p 0}+K_{i 0}\right) \\
K_{i e r}=G_{i p}\left(K_{p 1}+K_{i 1}\right)
\end{gathered}
$$

and

$$
K_{x p r}=G_{x p} K_{x 0}
$$

By substituting (41)-(45) into (40), we can derive the control input as

$$
\begin{aligned}
u= & \omega_{r}^{*}=K_{p n r} e_{\theta}^{\frac{1}{3}}+K_{p e r} e_{\theta} \\
& +K_{i n r} \int e_{\theta}^{\frac{1}{3}} d t+K_{\text {ier }} \int e_{\theta} d t+K_{x p r} \omega_{r}
\end{aligned}
$$

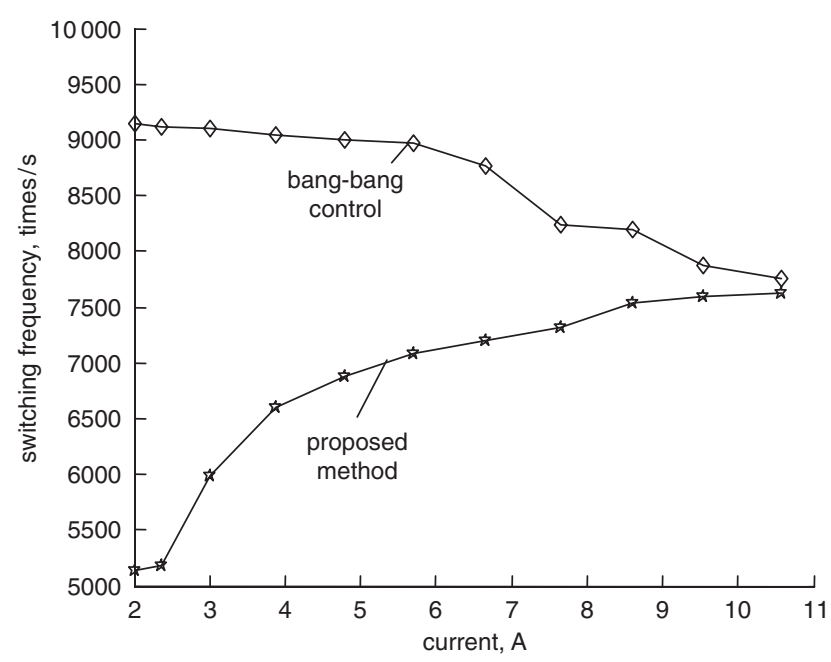

Fig. 5 The switching frequency to different loads

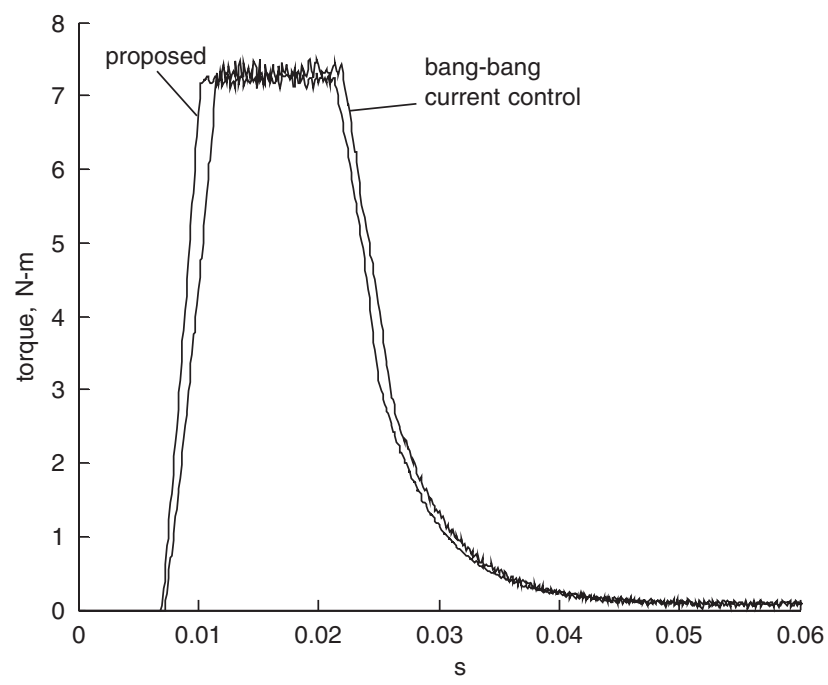

Fig. 6 The torque responses 

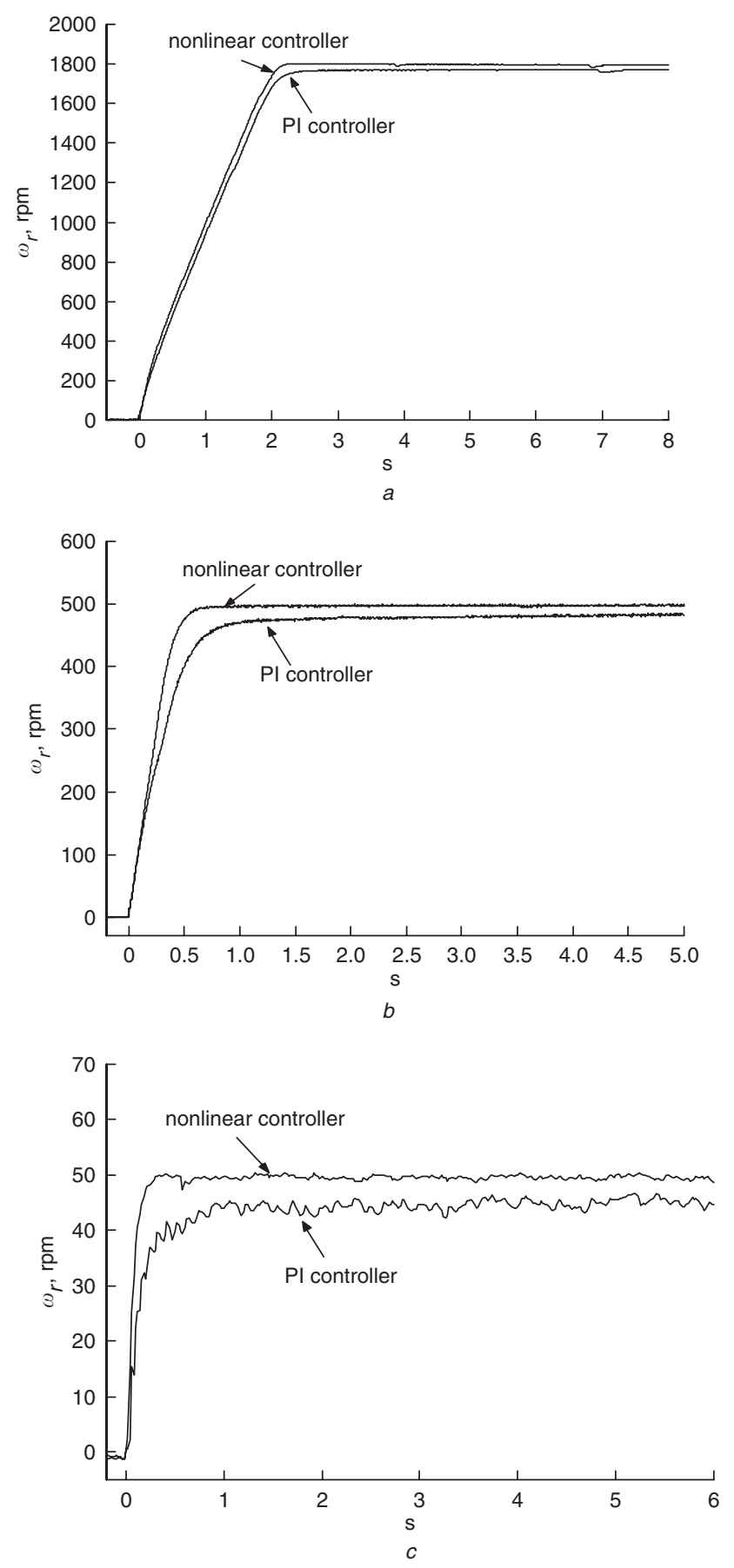

Fig. 7 The measured transient speed responses a $1500 \mathrm{r} / \mathrm{min}$ b $500 \mathrm{r} / \mathrm{min}$ c $50 \mathrm{r} / \mathrm{min}$

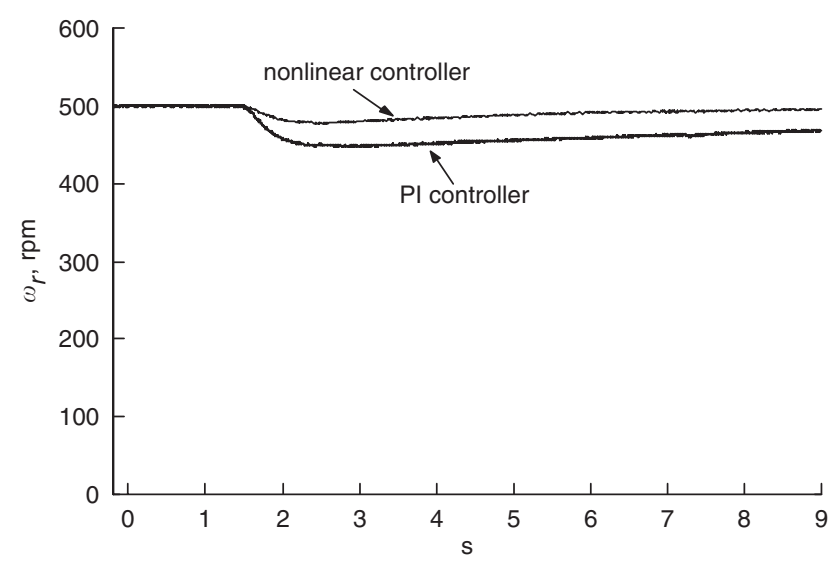

Fig. 8 The measured load disturbance responses
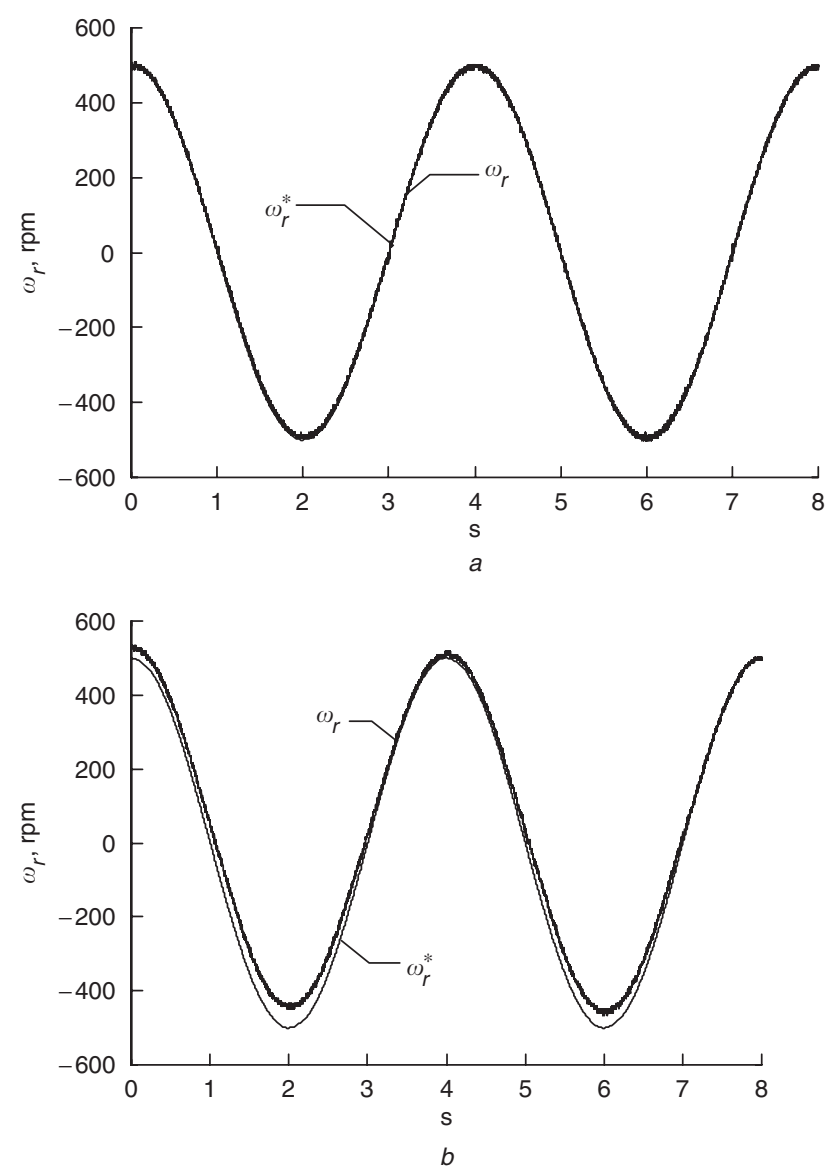

Fig. 9 The measured sinusoidal speed responses $a$ Nonlinear $b$ PI

\section{Experimental results}

The proposed system uses a 32-bit digital signal processor, TMS 320C30, to determine the PWM switching states and execute the control algorithms. The dc bus voltage of the inverter is $150 \mathrm{~V}$. The sampling interval of the current-loop is $100 \mu \mathrm{s}$, and the sampling intervals of the speed- and position-loop are $1 \mathrm{~ms}$, respectively. The motor is a 3-phase, 4 pole, rated speed $1800 \mathrm{r} / \mathrm{min}, 0.75 \mathrm{hp}$. It was manufactured by the Reliance Electric Company. The parameters of the motor are: $r_{s}=2 \Omega, L_{d}=0.148 \mathrm{H}$ $L_{q}=0.0672 \mathrm{H}, J=0.00239 \mathrm{~kg}-\mathrm{m}^{2}, \mathrm{~B}=0.012 \mathrm{~N} . \mathrm{m} / \mathrm{s}, \mathrm{P}_{\mathrm{o}}=4$ poles.

Several experimental results are shown here. Figures $3 a$ and $3 b$ show the measured line-to-line voltage of the motor. Figure $3 a$ is the result of the proposed PWM control. Figure $3 b$ is the waveform of the bang-bang PWM control. As can be observed, the proposed PWM method has a lower switching frequency than the traditional bang-bang control. Figures $4 a$ and $4 b$ show the measured a-phase currents of the motor. Figure $4 a$ is the current waveform of the proposed control method and Fig. $4 b$ is the waveform of the bang-bang control. The proposed method has lower harmonics than the bang-bang control. Figure 5 compares the switching times/s of the proposed method and bang-bang control. When the motor is operated at a heavy load, both of them have very similar switching times; however, when the motor is operated at a light load, the bang-bang control has twice the number of switching times as compared to the proposed method. 

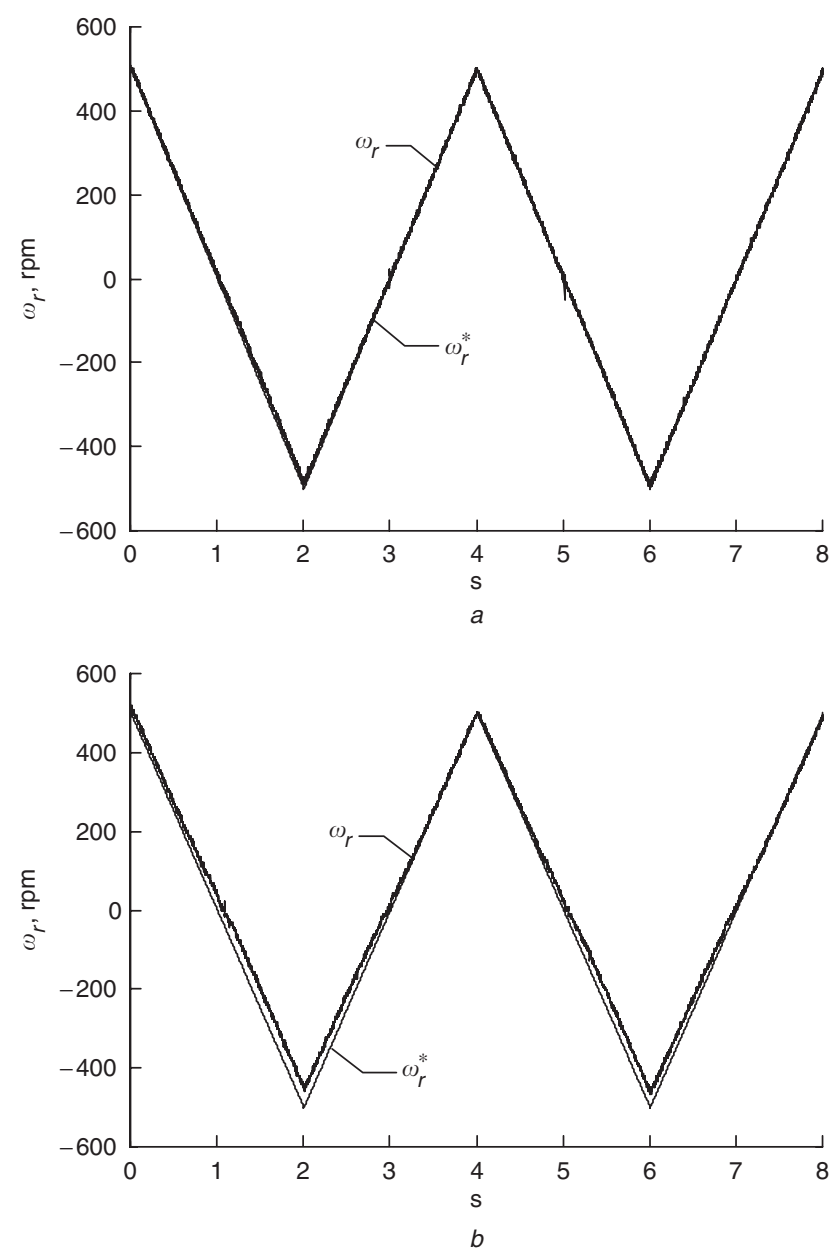

Fig. 10 The measured triangular speed responses $a$ Nonlinear $b$ PI

Figure 6 shows the tracking performance of the torque. Again, the proposed method performs better than the bang-bang control although the proposed method has a lower switching frequency than the traditional bang-bang control.

Figures $7 a, 7 b$, and $7 c$ show the measured transient speed responses of different speed commands. According to the measured results, the proposed nonlinear controller performs better than the PI controller at different operating speeds. Figure 8 shows the load disturbance responses when a $2 \mathrm{~N}-\mathrm{m}$ load is added to the motor at the speed of $500 \mathrm{r} / \mathrm{min}$. Again, the nonlinear controller has a lower speed dip than the PI controller. Figures $9 a$ and $9 b$ show the measured sinusoidal speed responses. As can be observed the nonlinear controller tracks the sinusoidal command well; however, the PI controller produces a lagging response. Figures $10 a$ and $10 b$ show the measured triangular speed responses. The nonlinear controller performs better again. Figures $11 a, 11 b$, and $11 c$ show the measured responses of position, velocity, and q-axis current of the nonlinear controller as the shaft of the motor is controlled from 180 degrees to -180 degrees. Figure 12 shows the load disturbance position response when a $2 \mathrm{~N}-\mathrm{m}$ load is added. Figures $13 a$ and $13 b$ show the measured sinusoidal position responses of the two controllers. The nonlinear controller performs better. Figures $14 a$ and $14 b$ show the measured triangular position responses. A similar conclusion can be obtained.
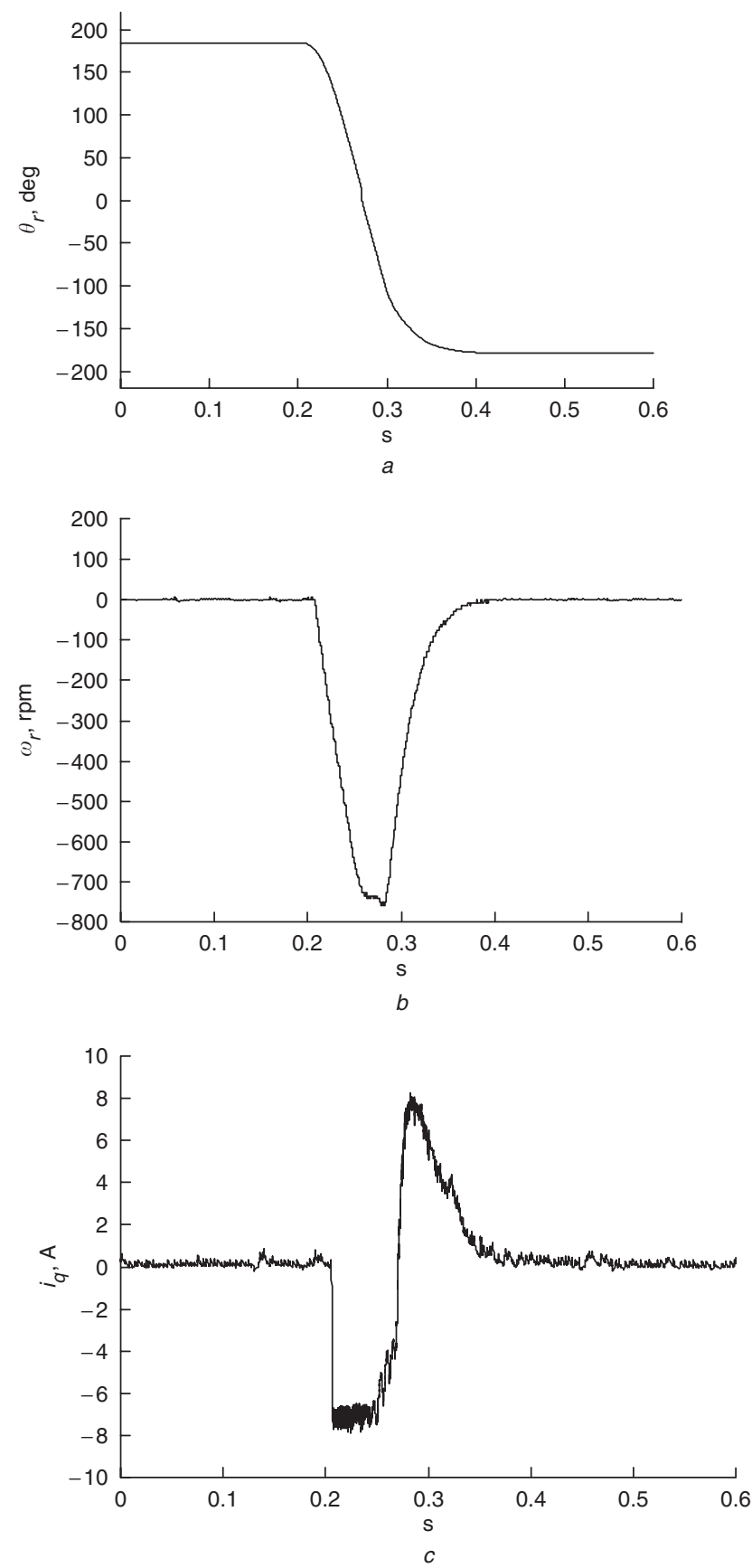

Fig. 11 The measured transient position responses $a$ Position

$b$ Velocity

$c$ q-axis current

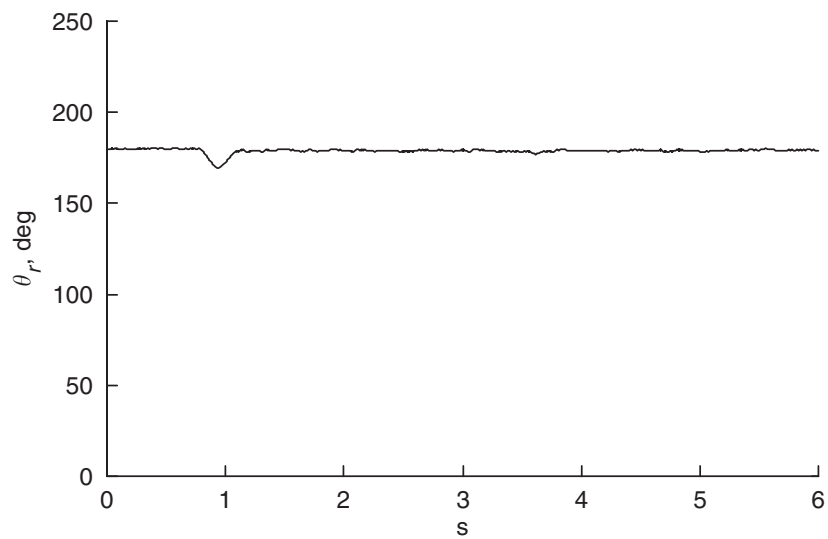

Fig. 12 The measured load disturbance position response at $2 \mathrm{~N}-\mathrm{m}$ load 

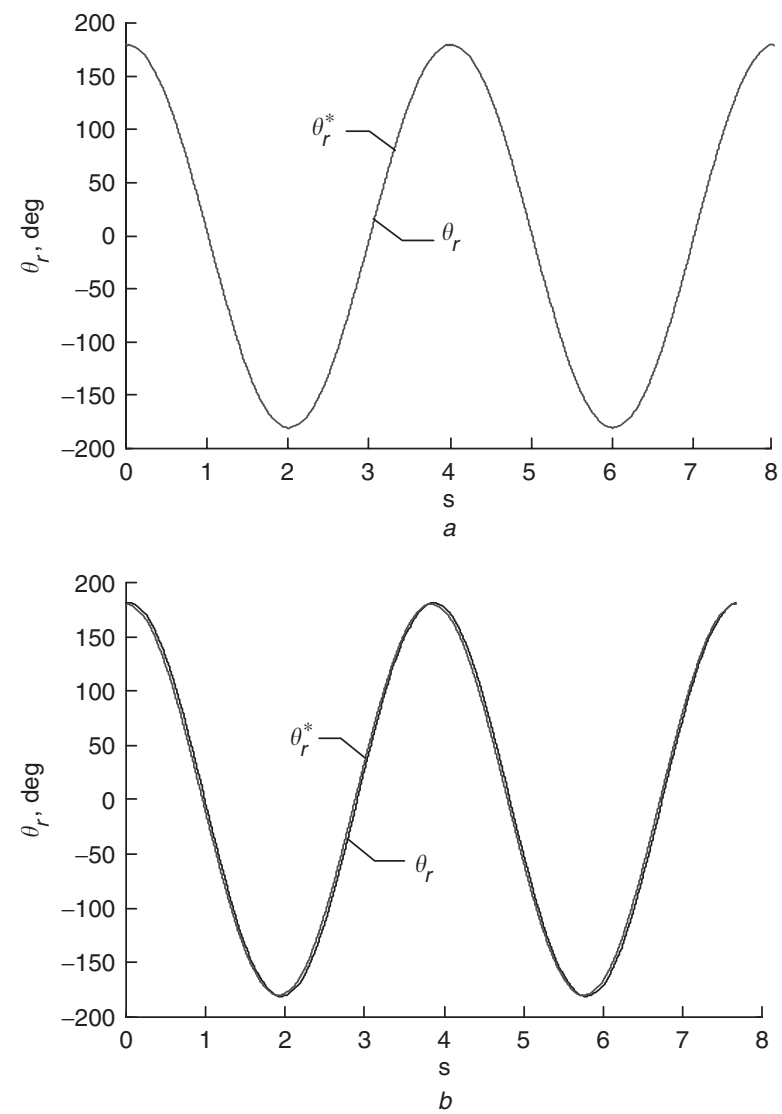

Fig. 13 The measured sinusoidal position responses $a$ Nonlinear

$b$ PI
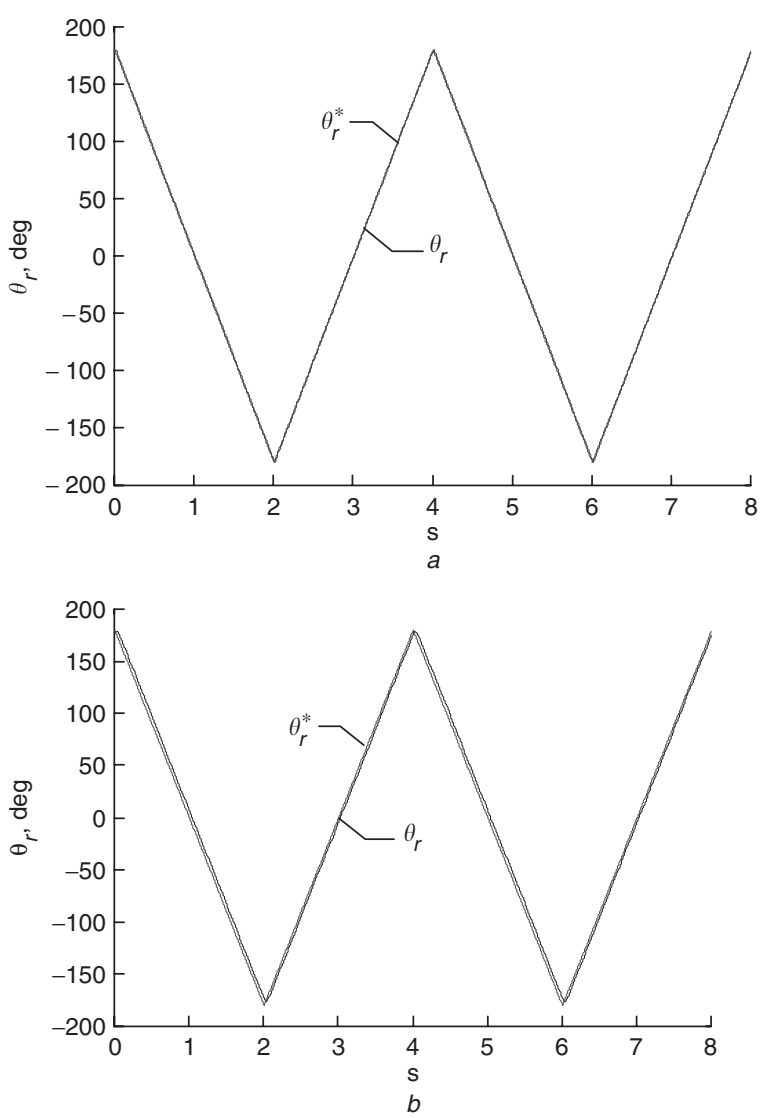

Fig. 14 The measured position responses $a$ Nonlinear $b$ PI

\section{Conclusions}

A new PWM strategy and a novel control algorithm have been proposed. The PWM strategy and the control algorithm are implemented by a 32-bit digital signal processor. As a result, the hardware is very simple and a fully digital control system is achieved. In addition, the proposed method can be applied to a speed control system and a position control system. Experimental results show that the proposed system has satisfactory performance and can be applied to a synchronous reluctance drive system.

\section{Acknowledgment}

The authors would like to acknowledge the financial support of the National Science Council in Taiwan, Republic of China, through grant NSC 93- 2213- E- 011012.

\section{References}

1 Bose, B.K.: 'Modern power electronics and AC drives' (Prentice Hall, NJ, 2002)

2 Consoli, A., Cavallaro, C., Scarcella, G., and Testa, A.: 'Sensorless torque control of Syncrel motor drives', IEEE Trans. Power Electron., 2000, 15, (1), pp. 28-35

3 Matsuo, T., and Lipo, T.A.: 'Rotor position detection scheme for synchronous reluctance motor based on current measurements', IEEE Trans. Ind. Appl., 1995, 31, (4), pp. 860-868

4 Consoli, A., Russo, F., Scarcella, G., and Testa, A.: 'Low- and zerospeed sensorless control of synchronous reluctance motors', IEEE Trans. Ind. Appl., 1999, 35, (5), pp. 1050-1057

5 Chen, C.G., Liu, T.H., Lin, M.T., and Tai, C.A.: 'Position control of a sensorless synchronous reluctance motor', IEEE Trans. Ind. Electron., 2004, 51, (1), pp. 15-25

6 Ciufo, P., and Platt, D.: 'Sensorless rotor position and speed estimation for a synchronous reluctance motor', IEE Proc. Electr., Power Appl., 2003, 150, (2), pp. 158-164

7 Kazmierkowski, M.P., and Malesani, L.: 'Current control techniques for three-phase voltage-source PWM converters: a survey', IEEE Trans. Ind. Electron., 1998, 45, (5), pp. 691-703

8 Bose, B.K.: 'Power electronics and variable frequency drives: technology and applications' (IEEE Press, NY, 2002)

9 Holtz, J., and Bayer, B.: 'Fast current trajectory tracking control based on synchronous optimal pulsewidth modulation', IEEE Trans. Ind. Appl., 1995, 31, (5), pp. 1110-1112

10 Platt, D.: 'Reluctance motor with strong motor anisotropy', IEEE Trans. Ind. Appl., 1992, 28, (3), pp. 652-658

11 Vagati, A., Pastorelli, M., and Franceschini, G.: 'High-performance control of synchronous reluctance motors', IEEE Trans. Ind. Appl., 1997, 33, (4), pp. 983-991

12 Kang, S.J., and Sul, S.K.: 'Highly dynamic torque control of synchronous reluctance motor', IEEE Trans. Power Electron., 1998, 13, (4), pp. 793-798

13 Lin, M.T., and Liu, T.H.: 'Design and implementation for a digital synchronous reluctance drive', IEEE Trans. Aerosp. Electron. Syst., 1998, 34, (4), pp. 1149-1164

14 Shyu, K.K., and Lai, C.K.: 'Incremental motion control of synchronous reluctance motor via multisegment sliding mode control method', IEEE Trans. Control Syst. Technol., 2002, 10, (2), pp. $169-176$

15 Lee, H.D., Kang, S.J., and Sul, S.K.: 'Efficiency-optimized direct torque control of synchronous reluctance motor using feedback linearization', IEEE Trans. Ind. Electron., 1999, 46, (1), pp. 192-198

16 Thanaa, S.E., Matthew, W.D., John, E.F., and Barry, W.W. 'Nonlinear robust control of a vector-controlled synchronous reluctance machine', IEEE Trans. Power Electron., 1999, 14, (6), pp. 1111-1121

17 Lin, M.S., and Liu, T.H.: 'Design and implementation of a robust controller for a synchronous reluctance drive', IEEE Trans. Aerosp. Electron. Syst., 1999, 37, (4), pp. 1344-1358

18 Chiang, H.K., and Tseng, C.H.: 'Integral variable structure controller with grey prediction for synchronous reluctance motor drive', IEE Proc. Electr. Power Appl., 151, (3), pp. 349-358

19 Shyu, K.K., Lai, C.K., and Hung, J.Y.: 'Totally invariant state feedback controller for position control of synchronous reluctance motor', IEEE Trans. Ind. Electron., 2001, 48, (3), pp. 615-624

20 Lyshevski, S.E.: 'Control systems theory with engineering applications' (Birkhauser, Boston, 2001) 


\section{Appendices}

\subsection{The selection of the parameters for the} proposed speed controller

The Lyapunov theorem is used to validate the stability of the drive system. We can take the derivation of the Lyapunov function and express it as:

$$
\dot{V}(\varepsilon)=\left(K_{p 0}+K_{i 0}\right) \varepsilon^{\frac{1}{3}} \dot{\varepsilon}+\left(K_{p 1}+K_{i 1}\right) \dot{\varepsilon} \dot{\varepsilon}
$$

The speed error is defined as

$$
\varepsilon=\omega_{r}^{*}-\omega_{r}
$$

and the derivation of speed error is

$$
\begin{gathered}
\dot{\varepsilon}=-\dot{\omega}_{r}=-\frac{1}{J}\left(T_{e}-T_{L}\right)=-\frac{1}{J}\left(K_{t}^{\prime} u-T_{L}\right) \\
K_{t}^{\prime}=\frac{3}{2} \frac{P_{0}}{2}\left(L_{d}-L_{q}\right) i_{d}
\end{gathered}
$$

where $K_{t}^{\prime}$ is the torque constant. The viscous frictional coefficient $B$ is ignored here because its value is small. By substituting (48)-(50) into (47), and doing some mathematical processes, we can derive

$$
\begin{aligned}
\dot{V}(\varepsilon)= & -\frac{K_{t}^{\prime}}{J}\left\{K_{p n}\left(K_{p 0}+K_{i 0}\right) \varepsilon^{\frac{2}{3}}+\left[K_{p e}\left(K_{p 0}+K_{i 0}\right)\right.\right. \\
& \left.+K_{p n}\left(K_{p 1}+K_{i 1}\right)\right] \varepsilon^{\frac{4}{3}}+K_{p e}\left(K_{p 1}+K_{i 1}\right) \varepsilon^{2} \\
& +K_{i n}\left(K_{p 0}+K_{i 0}\right) \varepsilon^{\frac{1}{3}} \int \varepsilon^{\frac{1}{3}} d t+K_{i e}\left(K_{p 0}+K_{i 0}\right) \varepsilon^{\frac{1}{3}} \\
& \times \int \varepsilon d t+K_{i n}\left(K_{p 1}+K_{i 1}\right) \varepsilon \int \varepsilon^{\frac{1}{3}} d t+K_{i e}\left(K_{p 1}+K_{i 1}\right) \varepsilon \\
& \left.\times \int \varepsilon d t\right\}+\left[\frac{1}{J}\left(K_{p 0}+K_{i 0}\right) \varepsilon^{\frac{1}{3}}+\frac{1}{J}\left(K_{p 1}+K_{i 1}\right) \varepsilon\right] T_{L}
\end{aligned}
$$

By letting

$$
K_{p n}<\left|K_{\text {in }} \int \frac{T^{\frac{1}{3}}}{\varepsilon^{3}} d t+\frac{T_{L}}{K_{t}^{\prime}}\right|
$$

and

$$
K_{p e}>\left|K_{i e} \int \varepsilon d t\right|
$$

We can derive

$$
\begin{aligned}
\dot{V}(\varepsilon)< & -\frac{K_{t}^{\prime}}{J}\left\{K_{i n}\left(K_{p 0}+K_{i 0}\right)\left(\varepsilon^{\frac{2}{3}}\left|\int \varepsilon^{\frac{1}{3}} d t\right|+\varepsilon^{\frac{1}{3}} \int \varepsilon^{\frac{1}{3}} d t\right)\right. \\
& +K_{i n}\left(K_{p 1}+K_{i 1}\right)\left(\varepsilon^{\frac{4}{3}}\left|\int \varepsilon^{\frac{1}{3}} d t\right|+\varepsilon \int \varepsilon^{\frac{1}{3}} d t\right) \\
& +K_{i e}\left(K_{p 0}+K_{i 0}\right)\left(\varepsilon^{\frac{4}{3}}\left|\int \varepsilon d t\right|+\varepsilon^{\frac{1}{3}} \int \varepsilon d t\right) \\
& +K_{i e}\left(K_{p 1}+K_{i 1}\right)\left(\varepsilon^{2}\left|\int \varepsilon d t\right|+\varepsilon \int \varepsilon d t\right) \\
& +\left[\left(K_{p 0}+K_{i 0}\right)+\left(\varepsilon^{\frac{2}{3}}\left|\frac{T_{L}}{K_{t}^{\prime}}\right|-\varepsilon^{\frac{1}{3}} \frac{T_{L}}{K_{t}^{\prime}}\right)\right. \\
& \left.\left.+\left(K_{p 1}+K_{i 1}\right)\left(\varepsilon^{\frac{4}{3}}\left|\frac{T_{L}}{K_{t}^{\prime}}\right|-\varepsilon \frac{T_{L}}{K_{t}^{\prime}}\right)\right]\right\} \leq 0
\end{aligned}
$$

When the drive system does not add an external load, the $T_{L}=0$. Then, (54) becomes

$$
\begin{aligned}
\dot{V}(\varepsilon)< & -\frac{K_{t}^{\prime}}{J}\left\{K_{i n}\left(K_{p 0}+K_{i 0}\right)\left(\varepsilon^{\frac{2}{3}}\left|\int \varepsilon^{\frac{1}{3}} d t\right|+\varepsilon^{\frac{1}{3}} \int \varepsilon^{\frac{1}{3}} d t\right)\right. \\
& +K_{i n}\left(K_{p 1}+K_{i 1}\right)\left(\varepsilon^{\frac{4}{3}}\left|\int \varepsilon^{\frac{1}{3}} d t\right|+\varepsilon \int \varepsilon^{\frac{1}{3}} d t\right) \\
& +K_{i e}\left(K_{p 0}+K_{i 0}\right)\left(\varepsilon^{\frac{4}{3}}\left|\int \varepsilon d t\right|+\varepsilon^{\frac{1}{3}} \int \varepsilon d t\right) \\
& \left.+K_{i e}\left(K_{p 1}+K_{i 1}\right)\left(\varepsilon^{2}\left|\int \varepsilon d t\right|+\varepsilon \int \varepsilon d t\right)\right\}<0
\end{aligned}
$$

\subsection{The selection of the parameters for the proposed position controller}

The Lyapunov theorem is used to validate the stability of the position control system. We can take the derivation of the Lyapunov function and express it as

$$
\begin{aligned}
\dot{V}\left(\varepsilon_{\theta}, \omega_{r}\right)= & \left(K_{p 0}+K_{i 0}\right) \dot{\varepsilon}_{\theta}^{\frac{1}{\varepsilon^{3}}} \dot{\varepsilon}_{\theta}+\left(K_{p 1}+K_{i 1}\right) \varepsilon_{\theta} \dot{\varepsilon}_{\theta} \\
& +K_{x 0} \omega_{r} \dot{\omega}_{r}
\end{aligned}
$$

By substituting (35) and (37) into (56), and doing some mathematical process, we can obtain

$$
\begin{aligned}
\dot{V}\left(\varepsilon_{\theta}, \omega_{r}\right)= & -\left(K_{p 0}+K_{i 0}\right) \varepsilon_{\theta}^{\frac{1}{3}} \omega_{r}-\left(K_{p 1}+K_{i 1}\right) \varepsilon_{\theta} \omega_{r} \\
& +K_{x 0}\left[\frac { K _ { p } K _ { t } ^ { \prime } } { J } \left(K_{p n r} \varepsilon_{\theta}^{\frac{1}{3}} \omega_{r}+K_{p e r} \varepsilon_{\theta} \omega_{r}\right.\right. \\
& +K_{i n r} \omega_{r} \int \varepsilon_{\theta}^{\frac{1}{3}} d t+K_{i e r} \omega_{r} \\
& \left.\left.\times \int \varepsilon_{\theta} d t+K_{x p r} \omega_{r}^{2}-K_{v} \omega_{r}^{2}\right)-\frac{T_{L} \omega_{r}}{J}\right]
\end{aligned}
$$

Next, by choosing

$$
K_{x 0}=\frac{J}{K_{p} G_{e p} K_{t}^{\prime}}
$$

Then, substituting (58) into (57), we can obtain

$$
\begin{aligned}
\dot{V}\left(\varepsilon_{\theta}, \omega_{r}\right)= & \frac{1}{G_{e p}}\left(K_{i n r} \omega_{r} \int \varepsilon_{\theta}{ }_{\theta}^{\frac{1}{3}} d t+K_{\text {ier }} \omega_{r}\right. \\
& \left.\int \varepsilon_{\theta} d t+K_{x p r} \omega_{r}^{2}-K_{v} \omega_{r}^{2}-\frac{T_{L} \omega_{r}}{K_{p} K_{t}^{\prime}}\right)
\end{aligned}
$$

In this paper, we select

$$
K_{v}>\left|K_{i n r} \int \frac{\frac{1}{3}}{\varepsilon_{\theta}^{3}} d t+K_{\text {ier }} \int \varepsilon_{\theta} d t+K_{x p r}+\frac{T_{L}}{K_{p} K_{t}^{\prime}}\right|
$$

Substituting (60) into (59), we can obtain

$$
\begin{aligned}
\dot{V}\left(\varepsilon_{\theta}, \omega_{r}\right)= & \frac{1}{G_{e p}}\left(-\left|K_{i n r} \int \varepsilon_{\theta}^{\frac{1}{3}} d t\right| \omega_{r}^{2}+K_{\text {inr }} \omega_{r}\right. \\
& \int \varepsilon_{\theta}^{\frac{1}{3}} d t-\left|K_{\text {ier }} \int \varepsilon_{\theta} d t\right| \omega_{r}^{2}+K_{\text {ier }} \omega_{r} \\
& \left.\int \varepsilon_{\theta} d t-\left|\frac{T_{L}}{K_{p} K_{t}^{\prime}}\right| \omega_{r}^{2}-\frac{T_{L} \omega_{r}}{K_{p} K_{t}^{\prime}}\right) \leq 0
\end{aligned}
$$


From (59)-(61), we can obtain and define

$$
\begin{aligned}
Z_{1}(t)= & \frac{1}{G_{e p}}\left(K_{i n r} \omega_{r} \int \varepsilon_{\theta}{ }_{\theta}^{\frac{1}{3}} d t+K_{i e r} \omega_{r}\right. \\
& \left.\times \int \varepsilon_{\theta} d t+K_{x p r} \omega_{r}^{2}-K_{v} \omega_{r}^{2}-\frac{T_{L} \omega_{r}}{K_{p} K_{t}^{\prime}}\right) \leq 0
\end{aligned}
$$

By integrating (62), we can derive

$$
\int_{0}^{t} Z_{1}(\tau) d \tau=V\left(\varepsilon_{\theta}(t), \omega_{r}(t)\right)-V\left(\varepsilon_{\theta}(0), \omega_{r}(0)\right)
$$

Because $\varepsilon_{\theta}(t)$ and $\omega_{r}(t)$ are bounded, from equation (63), we can obtain

$$
\lim _{t \rightarrow \infty} \int_{0}^{t} Z_{1}(\tau) d \tau(\tau) d \tau<\infty
$$

Because $Z_{1}(t)$ and $\dot{Z}_{1}(t)$ are bounded, and $Z_{1}(t)$ is a uniform and continuous function. From Barbalet's lemma, we can obtain

$$
\lim _{t \rightarrow \infty} z_{1}(t)=0
$$

Combining (61) and (65), we can conclude that the proposed position control system converges to a zero steady-state error. As a result, the position control system is an asymptotically stable system. 